\title{
Comparison of Four Methods to Estimate Urban Heat Storage
}

\author{
SARAH M. Roberts AND T. R. OKe \\ Department of Geography, The University of British Columbia, Vancouver, British Columbia, Canada
}

\section{S. B. GRIMMOND}

Atmospheric Science Program, Department of Geography, Indiana University, Bloomington, Indiana, and Environmental Monitoring and Modelling Group, Department of Geography, King's College London, London, United Kingdom

\author{
J. A. Voogt \\ Department of Geography, University of Western Ontario, London, Ontario, Canada
}

(Manuscript received 28 August 2005, in final form 14 April 2006)

\begin{abstract}
The relative performance of four independent methods to estimate the magnitude and diurnal behavior of net heat storage fluxes $\left(\Delta Q_{S}\right)$ in a city center is assessed. This heat flux is a significant but understudied component of the urban surface energy balance (SEB). Direct measurement of this SEB term at the local scale (horizontal length scale $\sim 10^{2}-10^{4} \mathrm{~m}$ ) is practically unattainable primarily because of the complex array of materials and the three-dimensionality of urban systems. Results of an 8-day summertime observational study at a site in the center of Marseille, France, are presented. This locale is an ideal environment for such research because of the warm, dry climate (hence the SEB is dominated by sensible heat exchanges) and the high density of tall buildings with thick walls (hence it has a large thermal mass that favors heat storage as a component of the SEB). Estimates of $\Delta Q_{S}$ derived as residuals in the SEB, after the remaining terms are measured directly, (termed RES) are compared with those calculated from a parameterization scheme [objective hysteresis model (OHM)], a local-scale numerical model [Town Energy Balance model (TEB)], and a bulk heat transfer method [thermal mass scheme (TMS)]. Inputs to the methods include observed meteorological data and morphometric properties of the urban site. All approaches yield a similar diurnal course. The OHM and TEB methods tend to slightly overestimate storage uptake by day when compared with the RES, whereas TMS slightly underestimates it. All methods underestimate heat storage release at night when compared with RES and show some sensitivity to wind speed, especially above about $5 \mathrm{~m} \mathrm{~s}^{-1}$. OHM estimates perform satisfactorily in the mean but miss short-term variability and are poor at night. TEB simulations show the best agreement with RES results, particularly at night. TMS values are comparable to those from the other methods, but its extensive input requirements render it almost impractical. Overall, the convergence of results is reassuring but the lack of a standard for quantifying heat storage and the spread of results mean this term remains a source of imprecision in urban energy balance measurement and modeling.
\end{abstract}

\section{Introduction}

Understanding the nature of energy partitioning at the surface of cities is prerequisite to gaining the proper insight and ability to model their climatic environments. Of particular relevance in the urban environ-

Corresponding author address: Prof. T. R. Oke, Department of Geography, The University of British Columbia, 1984 West Mall, Vancouver BC V6T 1Z2, Canada.

E-mail: toke@geog.ubc.ca ment is the role of the net heat storage flux $\Delta Q_{S}$, which can account for more than half of the daytime net radiation at highly urbanized sites such as downtown St. Louis, Missouri (Ching 1985), and central Mexico City, Mexico (Oke et al. 1999). The heat storage flux is the net uptake or release of energy from an urban system. It includes the volumetric changes of latent and sensible heat by the air, buildings, vegetation, and ground at the spatial scale of interest and extends from the height of the top of the roughness sublayer (RSL) down to the depth of zero vertical heat flux in the substrate (Oke 
TABLE 1. OHM empirical coefficients for individual surface covers used in Marseille.

\begin{tabular}{|c|c|c|c|c|}
\hline Surface & $a_{1}$ & $a_{2}(\mathrm{~h})$ & $a_{3}\left(\mathrm{~W} \mathrm{~m}^{-2}\right)$ & Source \\
\hline Gravel roof & 0.26 & 0.89 & -24.0 & Meyn (2000) \\
\hline Clay tile roof & 0.07 & 0.06 & -5.0 & S. K. Meyn (2005, personal communication) \\
\hline Impervious ground & 0.70 & 0.41 & -0.38 & $\begin{array}{l}\text { Average of Doll et al. (1985), Asaeda and Ca (2000), } \\
\text { Narita et al. (1984), and Anandakumar (1999) }\end{array}$ \\
\hline Vegetation & 0.32 & 0.54 & -27.4 & Doll et al. (1985) \\
\hline Water & 0.50 & 0.21 & -39.1 & Souch et al. (1998) \\
\hline
\end{tabular}

1988; Grimmond et al. 1991). The flux depends on the urban structure, the thermal properties of the urban materials (thermal conductivity, heat capacity), and the sun-surface-atmosphere coupling. Because of differences in these characteristics between urban and rural areas the nocturnal heat release from urban fabric is a major contributor to the nocturnal urban heat island effect (Oke et al. 1991). Also, $\Delta Q_{S}$ is important in many practical applications, for example, to assess building and pedestrian climates and to model evaporation, the convective sensible heat flux, and the boundary layer growth (Grimmond et al. 1991; Roth and Oke 1994; Taha 1997).

Conventional methods of directly measuring heat storage in simple environments, such as the use of soil heat flux plates in soils and low plant covers, is not easily adapted to an urban system. This is simply because the myriad surface types and their orientations and mutual shading set an almost impossible sampling challenge in order to obtain representative $\Delta Q_{S}$ values over the scale of interest. Attempts to sample urban $\Delta Q_{S}$ are usually restricted to subsets of distinct urban surfaces such as asphalt, concrete, and various roof assemblies (see Table 1; Grimmond and Oke 2002).

To compensate for these logistical impracticalities a local-scale soil-building-air volume concept is adopted (Oke 1988). The model is likened to a volumetric "black box" (Fig. 1), the bottom of which is the depth below the surface at which zero net heat flux occurs over the period of concern. The upper bound of this conceptual volume is the extent of the urban canopy layer (UCL; typically just above roof level) or the measurement level [which for turbulent fluxes should be greater than the height of the RSL, which is approximately 2-4 times the height of the main roughness elements (Oke 2004)]. This formulation has the benefit of allowing the complex spatial arrangement of individual energy sources and sinks to be neglected, because if horizontal advection is negligible, only energy fluxes through the top of the volume are considered. The net storage heat flux, therefore, includes heat conduction into or out of, and temperature changes by, every component within the black box (e.g., roofs, walls, roads, vegetation), as well as latent and sensible heat changes in the air volume (Oke and Cleugh 1987).

\section{Methods to estimate the urban heat storage flux}

Difficulties associated with direct measurement of urban $\Delta Q_{S}$ aside, it is imperative to find ways to estimate this energetic flux term in cities. Four methods that might be used to determine this flux are discussed here.

\section{a. Energy balance residual method (RES)}

Since the introduction of reliable fast-response sensors to measure the latent heat flux density, urban climate studies are able to determine $\Delta Q_{S}$ as the residual from direct observations of the net all-wave radiation $\left(Q^{*}\right)$, turbulent sensible $\left(Q_{H}\right)$, and latent $\left(Q_{E}\right)$ heat fluxes, that is,

$$
\Delta Q_{S}=\left(Q^{*}+Q_{F}\right)-\left(Q_{H}+Q_{E}\right) .
$$

where $Q_{F}$ is the anthropogenic heat flux resulting from vehicular emissions, space heating and cooling of buildings, industrial processing, and the metabolic heat release of homeotherms (Grimmond 1992; Sailor and Lu 2004). While the energy balance residual method is straightforward, its primary drawback is the accumulation in $\Delta Q_{S}$ of measurement errors of each surface energy balance (SEB) flux in (1), and the error of having neglected any unmeasured terms. Errors in the measured flux terms include those stemming from normal measurement inaccuracies plus the real spatial variability of the surface energy balance. It is well known that there is lack of energy balance "closure," even using the best instrumentation, methods, and extensive sites (e.g., Wilson et al. 2002). Further, this lack of closure is systematically biased to underestimate the turbulent terms (i.e., $Q^{*}-Q_{G}>Q_{H}+Q_{E}$ ). This means the RES standard flux density against which the other three methods are compared is probably always too large.

The source area ("footprint") of turbulent fluxes is a sensitive function of wind direction, surface roughness, and atmospheric stability (Schmid et al. 1991), so when 


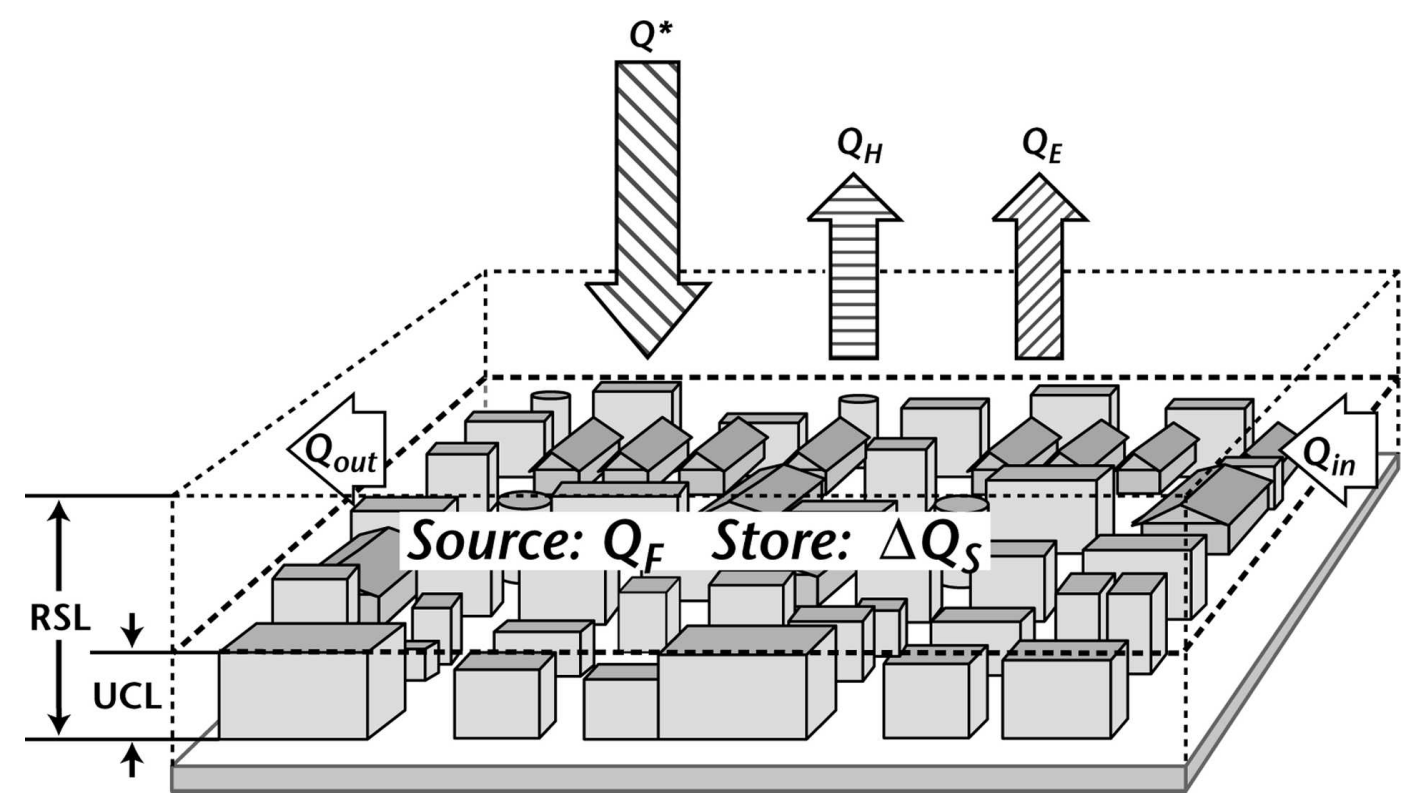

FIG. 1. Schematic illustration of the fluxes in the energy balance of an urban building-soil-air volume. The equivalent surface energy balance per unit surface area through the top of the volume is $Q^{*}+Q_{F}=Q_{H}+Q_{E}$ $+\Delta Q_{S} \pm \Delta Q_{A}$, where the net sensible and latent heat advection $\Delta Q_{A}=Q_{\text {in }}-Q_{\text {out }}$. Source: modified after Oke (1987).

its dynamic variation is combined with the threedimensional complexity of typical urban areas the resulting flux signal is highly variable. Over a period of days, however, averaging of the spatial extent of the source areas smoothes the variability. Herein we only consider time-averaged fluxes over the measurement period.

RES estimates also suffer from the inclusion of the almost immeasurable heat release of anthropogenic heat $\left(Q_{F}\right)$. The most obvious origins of urban anthropogenic contributions are combustion exhausts associated with both stationary (buildings, chimneys) and mobile (vehicle, human) sources. Plausible magnitudes of $Q_{F}$ for cities in the nonheating season can be found in the literature and are typically of the order of a few tens of watts per squared meter (Oke 1988; Kłysik 1996; Sailor and Lu 2004). However, in a modern city core with high-rise buildings and intense traffic, values can exceed $100 \mathrm{~W} \mathrm{~m}^{-2}$ (e.g., London, United Kingdom, see Harrison et al. 1984; Tokyo, Japan, see Ichinose et al. 1994).

The instruments used to measure $Q^{*}, Q_{H}$, and $Q_{E}$ are expected to sense most of the $Q_{F}$ contributions to the radiative and convective flux terms, but an undetermined fraction contributes to heat storage change in the building fabric. It is considered here that errors in RES estimates of $\Delta Q_{S}$ resulting from the inaccurate estimation of $Q_{F}$ and failure of the instruments to sense these contributions are small (a few tens of watts per squared meter).

Although measured $Q_{F}$ data are not available for the study site, Grimmond et al. (2004) estimate this term for central Marseille, France, using measured and modeled values of $Q_{F}$ from other cities such as London (Harrison et al. 1984), Łódź, Poland (Kłysik 1996), central Tokyo, (Ichinose et al. 1999), and several large cities in the United States (Sailor and Lu 2004). On the basis of these and other previous works, Grimmond et al. (2004) prescribe $Q_{F}$ at the Marseille site to vary between $15 \mathrm{~W} \mathrm{~m}^{-2}$ at night and $50 \mathrm{~W} \mathrm{~m}^{-2}$ for most of the daytime, with peaks of $75 \mathrm{~W} \mathrm{~m}^{-2}$ during the morning and afternoon commuter rush hours. The daily course and the timing of the peak values are based on observed fluxes of $\mathrm{CO}_{2}$ at the site. We take them to be an independent measure of human activity near the study site (Grimmond et al. 2004).

The residual method is also subject to errors because it does not explicitly consider net horizontal heat and moisture advection $\left(\Delta Q_{A}\right)$ into the black box volume (Fig. 1). To minimize such errors the measurement site is selected with considerable care. The aim is to ensure that observations are representative of the target surface cover and that surface heterogeneity does not lead to large flux variability with changes in wind direction. The measurement tower must be located in an area with extensive horizontal fetch and the sensors 
mounted in the constant flux (inertial) portion of the urban boundary layer (UBL), so that the subscale spatial variability of individual surface elements is no longer discernible (Oke 2004). Further, data are filtered by wind direction so that signals from target sectors can be considered.

Pigeon et al. (2003) make estimates of the advection term for the Marseille site using a network of temperature and humidity sensors. Their analyses show, for example, that on 10 July 2001 [yearday (YD) 191], the measurement site experienced a $50 \mathrm{~W} \mathrm{~m}^{-2}$ net gain in advected heat flux but this was compensated for in the moisture flux divergence $\left(62 \mathrm{~W} \mathrm{~m}^{-2}\right)$. The following day, 11 July 2001, followed suit with $122 \mathrm{~W} \mathrm{~m}^{-2}$ heat flux advection versus $137 \mathrm{~W} \mathrm{~m}^{-2}$ moisture flux divergence. Based on 4 days in and immediately after the period used here Pigeon et al. (2003) conclude that the advective fluxes of latent and sensible heat are of similar size but are opposite in sign, thereby essentially offsetting each other. Following their work, we conclude that horizontal heat and moisture advection, while present, especially during the passage of mesoscale seabreeze fronts, is not a major contributor to error in RES estimates of heat storage. Pigeon et al. (2006) found that on two days with similar radiative forcing (21-22 June, YD 172-173) the day with the smaller observed turbulent sensible heat flux (YD 173) has the more significant heat advection term and the slightly larger moisture advective flux (but with the reverse sign). Thus, it may be on individual days RES $\Delta Q_{S}$ is overestimated during the middle of the day.

\section{b. Parameterization (OHM)}

Estimates of urban heat storage flux can also be obtained with a parameterization scheme. Here values of $\Delta Q_{S}$ are calculated as functions of a point source value of $Q^{*}$ and surface material characteristics using the objective hysteresis model (OHM) of Grimmond et al. (1991). This method describes the observed nonlinear (hysteresis) relation between radiative forcing and heat storage changes for urban areas according to

$$
\Delta Q_{S}=\sum_{i=1}^{n}\left(f_{i} a_{1 i}\right) Q^{*}+\sum_{i=1}^{n}\left(f_{i} a_{2 i}\right) \frac{\partial Q^{*}}{\partial t}+\sum_{i=1}^{n}\left(f_{i} a_{3 i}\right),
$$

where $i$ is one of $n$ surface types of varying fraction $(f)$, such as roofs, walls, lawns, or roads. The time derivative of net radiation is approximated as $0.5\left(Q_{t+1}^{*}-Q_{t-1}^{*}\right)$, with $t=1 \mathrm{~h}$, and the $a$ coefficients are empirically derived from independent studies relating $\Delta Q_{S}$ to $Q^{*}$ over specific urban surface types. To apply this scheme at a particular site, an inventory of the local surface cover and corresponding $a$ coefficients is compiled. The appropriate source area locations and surface weightings are calculated with a flux footprint model (e.g., Schmid 1997), in combination with an urban geographic information system (e.g., Grimmond and Oke 1999), respectively.

Grimmond and Oke (1999) evaluated OHM against RES estimates from seven North American cities and showed it to perform well in downtown urban and suburban areas in light wind $\left(<2 \mathrm{~m} \mathrm{~s}^{-1}\right)$ conditions. The authors point out, however, that weaknesses in OHM's performance are partly attributed to the scheme's potential scale conflicts; that is, the coefficients derived for individual surfaces use a $Q^{*}$ value specific to each surface type, whereas the $Q^{*}$ measurement used in (2) is a local-scale average, taken tens of meters above roof level. Schmid et al. (1991) showed that although differences of measured $Q^{*}$ between sites versus a fixed site 25-30 m above the surface were small (less than 5\%), bias is likely introduced if the source area is made up of surfaces with contrasting radiation budgets. Given that $Q^{*}$ partly drives spatial and temporal variability in convective fluxes, OHM by extension, does not capture this variability. Further, other factors contributing to convective flux variability (surface moisture, micro- to mesoscale flow regimes, synoptic conditions) are not explicitly resolved by OHM. Another recognized drawback to the scheme is the paucity of available data describing the relation between $\Delta Q_{S}$ and $Q^{*}$ for many urban surfaces (especially roofs).

\section{c. Numerical modeling (TEB)}

The Town Energy Balance (TEB) model (Masson 2000) bridges the micro- and mesoscales and simulates the local-scale urban surface energy budget for use in mesoscale atmospheric models either in an online or offline mode. The TEB scheme performs surfaceatmosphere coupling and its primary aim is to parameterize surface-atmosphere turbulent fluxes into the lowest level of mesoscale atmospheric models, that is, through the top of the UCL. TEB uses local canyon geometry to simulate the radiative, thermal, moisture, and wind effects produced by the presence of buildings and streets. The model simulates the heat and water exchanges and climate of three generic surfaces-roof, wall, and road. TEB can be run on its own for highly urbanized sites. For areas that include vegetated tiles, Noilhan and Planton's (1989) Interactions between Soil, Biosphere, and Atmosphere (ISBA) scheme for vegetated areas can be added. The model is forced with literature-based surface thermal parameters and observed or simulated atmospheric and radiation data 
from above roof level. Anthropogenic heat and vapor releases from buildings, vehicles and chimneys can also be added. An aerodynamic resistance network couples the surfaces, the canyon, and the above-roof air layers. The scheme allows many of the physical effects associated with the urban heat, mass, and momentum balances to be appropriately reproduced, including canyon radiative trapping (both shortwave and longwave), momentum fluxes, heat conduction, and interception of rain and snow. A description of the model is given in Masson (2000) and the slightly modified version used here is found in Lemonsu et al. (2004).

Offline evaluations of TEB have been conducted against measured flux and temperature values from three dry sites-the downtown city center of Mexico City, a light industrial site in Vancouver, British Columbia, Canada (Masson et al. 2002), and the current central site in Marseille (Lemonsu et al. 2004). Comparisons with field observations show the TEB is able to simulate $Q^{*}$ to $<10 \mathrm{~W} \mathrm{~m}^{-2}$ and to correctly partition the radiation forcing into turbulent and storage heat fluxes to within a few tens of watts per squared meter.

\section{d. Thermal mass scheme (TMS)}

Estimates of urban $\Delta Q_{S}$ also can be derived from basic concepts of heat conduction and volumetric heat storage in a material. Following the "struktur" model of Peikorz (1987), a thermal mass scheme (TMS) is constructed whereby exterior and interior surface temperature changes and information on the thermal properties and construction are combined to approximate $\Delta Q_{S}$,

$$
\Delta Q_{S}=\sum_{i=1}^{n} \Delta Q_{S_{i}}=\sum_{i=1}^{n} \frac{1}{A_{i}} \int C_{i} \frac{\Delta T}{\Delta t} d V_{i},
$$

where the index $i$ identifies $n$ surface types within the urban volume, $A_{i}$ is the surface area of component $i$ within the system, $C_{i}$ is the heat capacity ( $\mathrm{MJ} \mathrm{m}^{-3} \mathrm{~K}^{-1}$ ) of material $i, \Delta T / \Delta t$ is the volumetric change in temperature over a given time period $\left(\mathrm{K} \mathrm{s}^{-1}\right)$, and $d V_{i}$ is the element volume. When integrated over the UCL, (3) describes changes in heat storage out of the top of the UCL, resulting from the conductive fluxes into and out of each built component (which may be composed of multiple layers) within the system.

Implementation of this scheme in an urban system requires knowledge of the construction of the built volumes, the surface types and their orientation, mass and abundance within the target source area (similar to OHM requirements), plus a large sample of exterior and interior building temperatures to characterize the volume-averaged $\Delta T / \Delta t$. The volume over which (3) is considered is the same as the black box model de- scribed in section 1. Because the mass contributions of air and vegetation to the overall mass of the volume are usually very small in comparison with the other "solid" components of the UCL volume, these are only necessary if completeness is required (Kerschgens and Hacker 1985).

\section{The lack of a "standard"}

Unfortunately there is no accepted standard to determine urban heat storage, because there is no instrument or technique available to give "correct" values against which to calibrate other methods. In this regard it is similar to the study of roughness or anthropogenic heat or pollutant emissions at the city scale. Further, it is not even possible to develop meaningful error analyses of the methods. Each is open to one or more sources of error resulting from instrumental or methodological imperfection (RES, OHM, TEB, TMS), the physical impossibility of conducting adequate sampling (OHM, TMS), the inadequacy and oversimplification inherent in parameterizations and the nontransferability of their coefficients (OHM, TEB), the limits of numerical methods (TEB), or "validations" that are also unable to appeal to a standard (OHM, TEB, TMS).

The methods used here are genuinely independent. They depend on very different approaches and overlap is minimal; RES and OHM both use measured $Q^{*}$, TEB and TMS both use the same dimensions and thermal properties as those of the built materials, and TEB and OHM share the same surface cover fractions.

This study arbitrarily chose to use RES values as the reference for comparison. It is our experience that at this point most workers in the field consider RES estimates derived from high-quality observational studies to probably be closest to the correct value, even though in themselves they are not "measured." However, as outlined in section 2a, they remain subject to several significant errors in instruments, site variability, a systematic bias in SEB closure, and neglect of anthropogenic and advective heat terms. At any site and time, depending on whether they reinforce or offset each other, these errors could vary from minor to substantial. For example, at night, when absolute energy values are small, the uncertainty in assigning a magnitude to $Q_{F}$ and the known tendency of eddy covariance errors to grow in light flow (Wilson et al. 2002) could combine to give large percentage error in RES storage values. Hence, one can envisage that for a large, cold winter city at night with weak winds, where space heating is large, errors could be as large as the storage itself. Users should try to be aware of such limitations and consider the relative size of errors in environments very different from those in this study. 
RES values are selected as the reference set but only in the sense that they are a common unit for comparison purposes. We suspect they may be systematically too large because of the SEB closure and advective errors. This should be borne in mind when considering the results and conclusions.

\section{Method}

Field measurements and site surveys necessary to implement the four schemes were performed at a site in central Marseille $\left(43.29^{\circ} \mathrm{N}, 5.38^{\circ} \mathrm{E}, 13 \mathrm{~m} \mathrm{MSL}\right)$ during intense observation periods IOP 3, ABL IOP, and IOP 4 of the Expérience sur Site pour Contraindre les Modèles de Pollution Atmosphérique et de Transport d'Emissions (ESCOMPTE) field campaign (Mestayer et al. 2005) from 4 to 11 July 2001 (YD 185-192).

\section{a. Study site}

The densely built-up center of Marseille covers an area of approximately $2 \mathrm{~km} \times 2 \mathrm{~km}$ and is bordered by the Mediterranean Sea to the west (Mestayer et al. 2005). The study site was chosen to be representative of the area, and is relatively homogeneous and distant from changes of urban structure and cover. The site consists primarily of massive limestone and granite buildings built in the nineteenth century with walls as thick as $1 \mathrm{~m}$, and sloping roofs with clay tile or flat with pebble over tar or a membrane. The buildings are the tallest roughness elements, typically about five stories, with a mean height of $15.6 \mathrm{~m}$ (Grimmond et al. 2004). Street canyons are narrow and deep (Fig. 2) with little surrounding vegetation (mostly trees in courtyards and along street boulevards). Roads and sidewalks are constructed of asphalt and concrete, respectively. The average complete-to-plan area ratio (or the 3D aspect ratio; Voogt and Oke 1997) $\lambda_{c}$ for a 1000-m-radius area around the tower is 2.02 . The average 3D surface cover is $49 \%$ walls, $30 \%$ roofs, $13 \%$ impervious ground, and $8 \%$ vegetation.

Weather conditions during the IOP were characteristic of the Mediterranean summer climate (average air temperature $24^{\circ} \mathrm{C}$ and relative humidity $60 \%$; Fig. 3). There was no precipitation and little cloud cover throughout the IOP, so wind was the main discriminating variable used to classify days. Because of the complex coastline the sea-breeze system, which held for about half of the IOP (YD 188-191), gave daytime winds from the northwest or southeast. Synoptic flow of varying speed and direction, but with generally light $\left(<5 \mathrm{~m} \mathrm{~s}^{-1}\right)$ winds during the night and morning, characterized the other half of the IOP (YD 185-187, 192).
Generally, the sea-breeze flow was cooler and moister than the synoptic air mass (Pigeon et al. 2003).

\section{b. Observations}

The energy balance data used in the RES, OHM, and TEB $\Delta Q_{S}$ estimates were collected using eddy covariance and radiometric measurement techniques. Fastand slow-response instruments were mounted on an adjustable pneumatic tower erected on the roof of a 20$\mathrm{m}$-high building in the city center. Sensors were located above the roughness sublayer in the constant flux layer, between 34.6 and $43.9 \mathrm{~m}$ above street level (demonstrated in Grimmond et al. 2004). A sonic anemometer (R. M. Young 81000) measured vertical wind speed and air temperature and an infrared gas analyzer ( $\mathrm{Li}-\mathrm{Cor}$ 7500) measured humidity fluctuations at $10 \mathrm{~Hz}$. Sensible heat and moisture flux covariances were determined over 60-min periods (see Grimmond et al. 2004 for processing details). All components of the net radiation budget were sensed with a net radiometer (Kipp \& Zonen CNR1) mounted on a boom at the top of the tower that extended $2.7 \mathrm{~m}$ horizontally.

For the TMS method a network of fixed infrared radiation thermometers (IRTs) (Everest Interscience, Inc., Model 4000A and 4000.4GL) were used to monitor external surface radiant temperatures. Each sensor was calibrated first against a standard calibration plate in the field to convert to blackbody and then in a laboratory using a stirred water bath and a blackbody calibration chamber. The resultant data are blackbodyapparent temperatures. The IRTs (some with $15^{\circ}$ others with $60^{\circ}$ fields of view) were mounted to optimize the canyon wall and road surface areas "seen" by each sensor. Roads and canyon walls oriented in both northsouth and east-west directions were sensed. IRTs also sensed the surface temperature of the two predominant roof types: flat pebble-topped and clay tile roofs with $\sim 17^{\circ}$ pitch, in the four cardinal compass directions. Supplementary external wall and roof surface temperature data were gathered with an infrared scanner (FLIR Systems ThermaCam SC500) located at the tower site to take thermal image snapshots every 5 min of a target area that included a variety of other wall and roof surfaces represented in the area. Interior building wall surface and air temperatures were monitored with batterypowered dataloggers containing thermistor sensors (Onset Computer Corp., HOBO loggers).

\section{c. Implementation of the schemes}

\section{1) Objective hysteresis MODEL}

Appropriate $a$ coefficients, derived or modeled for urban surfaces, are needed to apply OHM to this site 

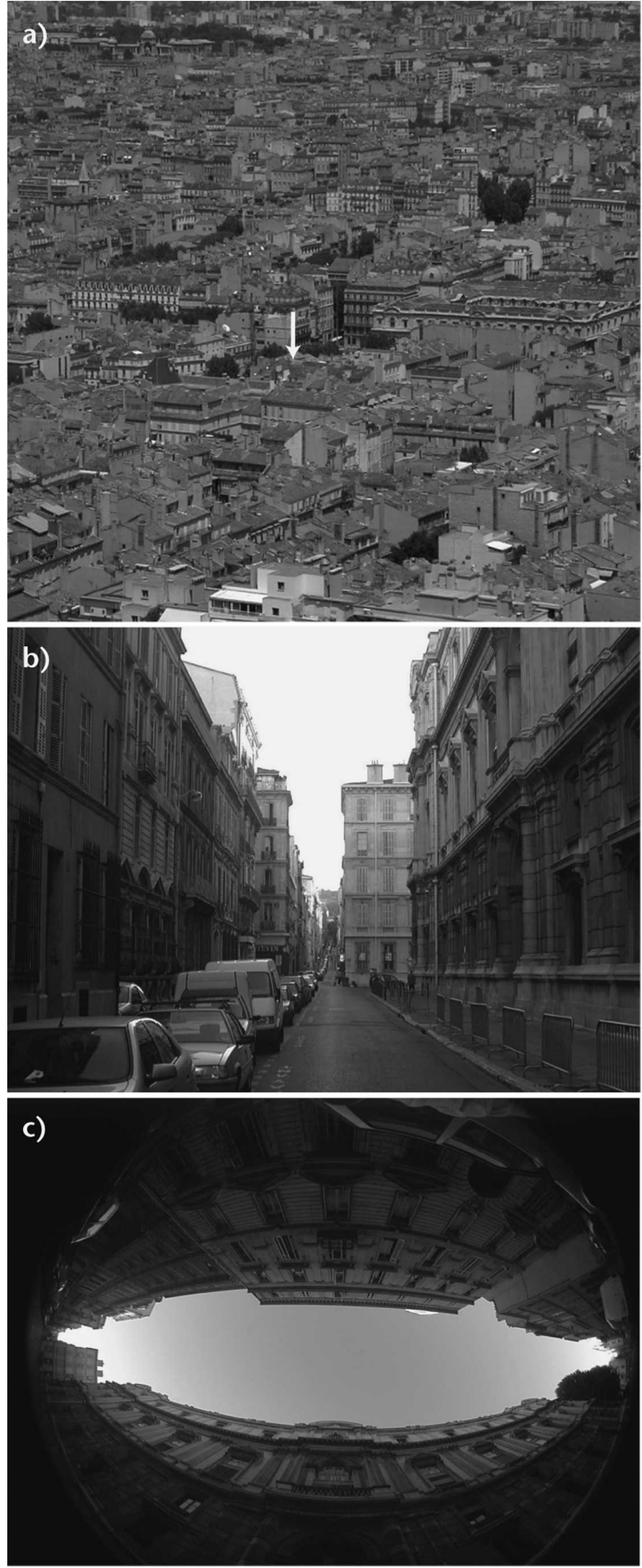

FIG. 2. The Marseille measurement site including (a) the tower location relative to its surrounding urban structure, (b) an urban canyon typical of those in the measurement domain (note the dimensions, materials, and shade patterns), and (c) a fish-eye lens view from the base of the same canyon. For another detailed view, but at roof-level showing the roof tiles, see Salmond et al. (2005b).
(Table 1). A significant fraction of the plan surface area of the Marseille site consists of clay tile roofs, for which there are no published $a$ values. Therefore, the Simplified Transient Analysis of Roofs (STAR) model of Wilkes (1989) was used to simulate the radiative and conductive heat fluxes necessary to approximate these coefficients. The plan areas of tile roofs, flat pebbletopped roofs, impervious ground, vegetation, and water that contribute to the SEB vary with the direction and size of the turbulent flux source area for each hourly period. Using flux source area calculations and a detailed survey of surface cover, OHM is able to account for the dynamics of the source areas and generate heat storage fluxes unique to each hour. An alternative approach to implementing OHM, recommended by Grimmond and Oke (1999), is to assume a static source area by applying average surface cover values to (2). Both approaches generate similar results [average difference over all hours $\sim 0.05 \mathrm{~W} \mathrm{~m}^{-2}$, overall reduction in bias (OHM-RES) attributable to using a static domain $\sim 0.12 \mathrm{~W} \mathrm{~m}^{-2}$ ]. A static source area is used here.

\section{2) Town Energy Balance model}

The original TEB formulation has been modified as outlined by Lemonsu et al. (2004) to include the thermal production of turbulence. This is done by adding the free-convection velocity term $w^{*}$ developed from Monin-Obukhov similarity theory. In this study TEB is run over a static modeling domain that assumes homogeneous surface characteristics within a circle of $500-\mathrm{m}$ radius around the measurement tower. The alternative would be to use a dynamic modeling domain, which takes into account the varying size and location of source areas resulting from changing wind and stability conditions. Sensitivity analyses by Lemonsu et al. (2004) indicate that a static domain is suitable for this site, because surface characteristics are relatively homogeneous. They also note that the additional computational requirements of the dynamic formulation do not yield significantly different or improved results.

The input parameters used to initialize TEB are listed in Tables 2 and 3. Meteorological observations taken from the top of the flux tower forced the model at a 30-min time step. As with the RES method, the high volume of vehicular traffic at this site necessitates a prescribed daily cycle of $Q_{F}$ in TEB simulations. The pattern used is identical to that of the RES method-15 $\mathrm{W} \mathrm{m}{ }^{-2}$ at night and $50 \mathrm{~W} \mathrm{~m}^{-2}$ during the day, with peaks of $75 \mathrm{~W} \mathrm{~m}^{-2}$ corresponding to peaks in the human activity cycle, especially during the commuter rush 


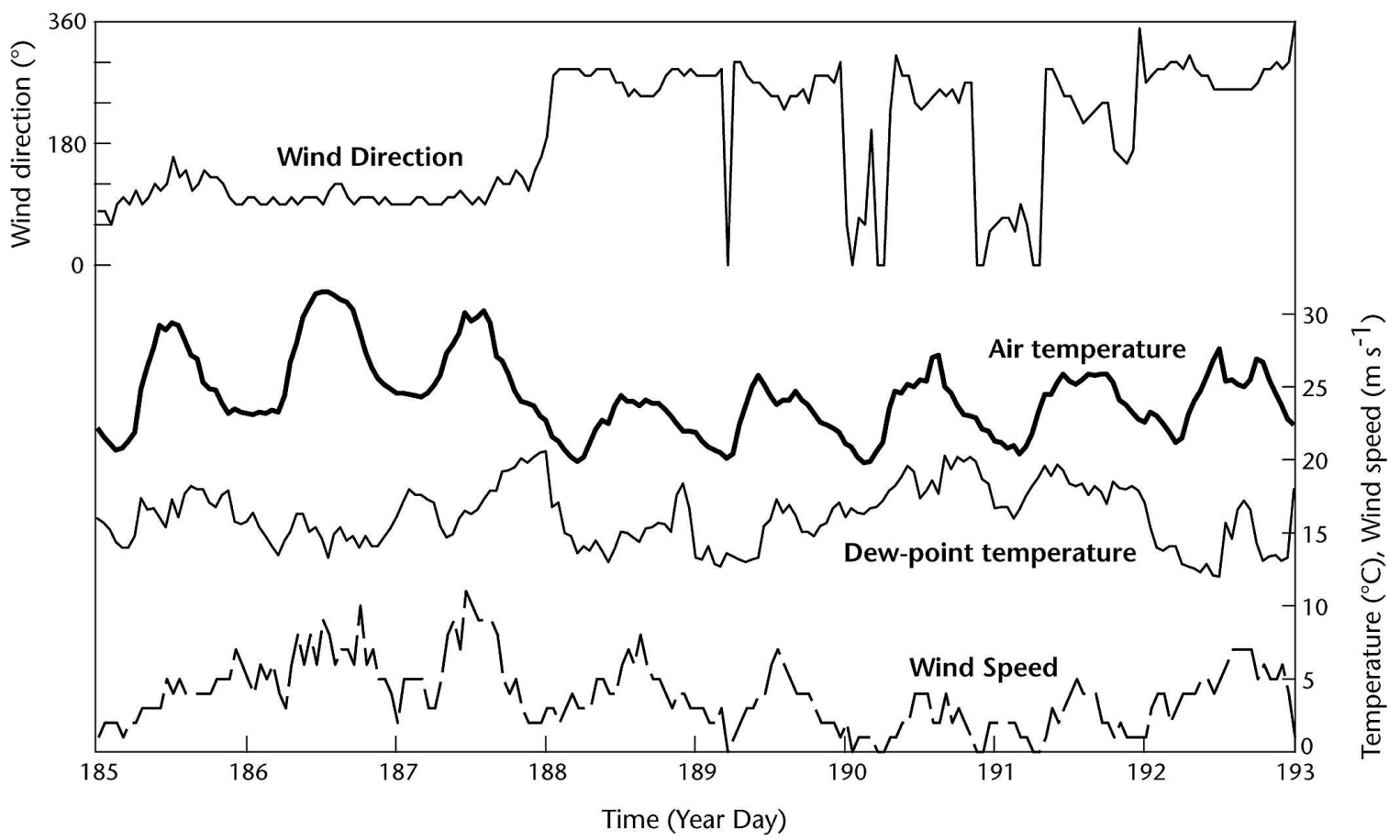

FIG. 3. Mean hourly meteorological conditions over the study period at Marseille-Marignane (World Meteorological Organization ID 07650), which is the reference climate station for the area and part of the Global Station Network.

hours (see Fig. 4). Surface thermal parameters, emissivities, and albedo values used in TEB are derived from the literature (ASHRAE 1993; Oke 1987) and field measurements.

\section{3) Thermal Mass SCHEME}

Measured surface temperatures of roof, wall, and road facets, and of interior building walls, combined with user-defined surface layer thermal properties and thickness are used to implement the TMS. To achieve consistency with TEB forcing parameters (Tables 2 and 3 ), four assumptions are made. First, each primary built surface type (e.g., roof, road, and wall) is subdivided into two categories according to surface material (e.g., gravel, tile, asphalt, concrete, etc.; Table 2). The proportion of surface area occupied by each subcategory within the UCL volume is derived from site surveys and aerial photographs. Second, the depth and material composition of the active layer of each surface subcategory is user defined. Each layer is assumed to be flush with the next (unless an air layer is specified). Third, the material heat capacity $C$ of each layer is integrated with respect to volume, resulting in an average $C$ for the entire material volume. Fourth, average heat capacity values for each surface type are calculated by weighting subcategory values with respect to their surface coverage.

\section{Results and discussion}

\section{a. Observed surface energy balance and RES}

The relative importance of each energy flux to the measured SEB at this highly urbanized site for all-sky and wind conditions during the IOP is shown in Fig. 4. A more detailed discussion of the energy regime at this site is given by Grimmond et al. (2004). The warm, dry climate and scarcity of local vegetation in the central district cause the evaporative heat flux $\left(Q_{E}\right)$, to be the smallest flux in the day and to hover near zero through the night. Trees are the main water sources; lesser amounts come from fountains, street washing, and vehicle exhaust. The convective sensible heat flux $\left(Q_{H}\right)$ is the dominant daytime energy use, accounting for nearly $70 \%$ of the energy input $\left(Q^{*}+Q_{F}\right)$. As is now well documented for other heavily built-up sites (Oke 1988; Grimmond and Oke 2002; Christen and Vogt 2004; Offerle et al. 2005), $Q_{H}$ remains positive at night. This is driven by the release of heat from storage in the built fabric and is related to the venting of sensible heat from the UCL (Salmond et al. 2005a). The heat originates from the canyon surfaces that remain warm at night and is sufficient to support a weakly unstable mixing layer in the lower part of the nocturnal UBL. The venting of heat from the canyons into the UBL continues into the early morning hours (Salmond et al. 2005a). This gives 
TABLE 2. Surface property inputs used in the TEB and TMS methods for the static modeling domain $(0.5-\mathrm{km}$ radius around the tower). See Table 3 for thermal properties of materials.

\begin{tabular}{|c|c|}
\hline Parameter & Input value \\
\hline \multicolumn{2}{|l|}{ Cover fractions } \\
\hline Natural cover & 0.136 \\
\hline Water & 0.000 \\
\hline Urban cover & 0.864 \\
\hline Building fraction & 0.595 \\
\hline Road fraction & 0.269 \\
\hline \multicolumn{2}{|l|}{ Geometric parameters } \\
\hline Building height & $15.6 \mathrm{~m}$ \\
\hline Building aspect ratio: $H / L$ & 1.14 \\
\hline Canyon aspect ratio: $H / W$ & 1.63 \\
\hline Roughness length & $1.90 \mathrm{~m}$ \\
\hline \multicolumn{2}{|l|}{ Road properties } \\
\hline Materials & $\begin{array}{l}\text { Asphalt and concrete } \\
\text { over dry soil }\end{array}$ \\
\hline Albedo & 0.08 \\
\hline Emissivity & 0.94 \\
\hline Momentum roughness length & $0.05 \mathrm{~m}$ \\
\hline \multicolumn{2}{|l|}{ Roof properties } \\
\hline Materials & $\begin{array}{l}\text { Tile or gravel over concrete, } \\
\text { wood, and insulation }\end{array}$ \\
\hline Albedo* & 0.22 \\
\hline Emissivity & 0.90 \\
\hline Momentum roughness length & $0.15 \mathrm{~m}$ \\
\hline \multicolumn{2}{|l|}{ Wall properties } \\
\hline Materials & $\begin{array}{l}\text { Stone walls, wood } \\
\text { window shutters }\end{array}$ \\
\hline Albedo & 0.20 \\
\hline Emissivity & 0.90 \\
\hline Momentum roughness length & $0.15 \mathrm{~m}$ \\
\hline \multicolumn{2}{|l|}{ Temperature initialization } \\
\hline Inside building temperature & $25.0^{\circ} \mathrm{C}$ \\
\hline Deep soil temperature & $17.0^{\circ} \mathrm{C}$ \\
\hline Roof surface temperature & $20.0^{\circ} \mathrm{C}$ \\
\hline Road surface temperature & $23.5^{\circ} \mathrm{C}$ \\
\hline
\end{tabular}

* Roof albedo is a weighted average from measurements and the literature: 0.28 for new tile roofs, 0.21 for gravel roofs, and 0.15 for darker tile roofs.

a pronounced hysteresis relation between $Q_{H}$ and $Q^{*}$. The RES estimate of $\Delta Q_{S}$ in Fig. 4 is broadly similar to those measured elsewhere (Grimmond and Oke 1999). The dip in values in the early afternoon for the IOP is slightly anomalous in comparison with the full 21-day dataset for Marseille (see Fig. 7 of Grimmond et al. 2004). Heat storage uptake is almost equal to convection in the morning, but the daytime peak of $\Delta Q_{S}$ precedes that of $Q_{H}$. Even before sunset the release of heat from storage is large, and from midnight onward the release of stored heat from the building air volume, plus the anthropogenic heat, supports all of the radiative and turbulent losses. The full Marseille dataset shows that heat sharing between storage and convection differs between morning and afternoon, depending on the
TABLE 3. Thermal properties of roofs, walls, and roads used in TEB and TMS for the Marseille site. Layer sequence: 1 is nearest to the surface, $d$ : layer thickness (m), $C$ : heat capacity of layer (MJ $\left.\mathrm{m}^{-3} \mathrm{~K}^{-1}\right)$, and $k$ : thermal conductivity $\left(\mathrm{W} \mathrm{m}^{-1} \mathrm{~K}^{-1}\right)$.

\begin{tabular}{|c|c|c|c|c|c|}
\hline \multicolumn{2}{|l|}{ Roofs } & \multicolumn{2}{|c|}{ Gravel (11.4\%) } & \multicolumn{2}{|c|}{ Tile $(88.6 \%)$} \\
\hline \multirow[t]{3}{*}{ Layer 1} & $d$ & 0.02 & Gravel & 0.02 & Tile \\
\hline & $C$ & 1.769 & & 1.769 & \\
\hline & $k$ & 1.400 & & 0.840 & \\
\hline \multirow[t]{3}{*}{ Layer 2} & $d$ & 0.15 & Concrete & 0.15 & Concrete \\
\hline & $C$ & 1.500 & & 1.500 & \\
\hline & $k$ & 0.930 & & 0.930 & \\
\hline \multirow[t]{3}{*}{ Layer 3} & $d$ & 0.12 & Insulation & 0.12 & Insulation \\
\hline & $C$ & 0.290 & & 0.290 & \\
\hline & $k$ & 0.050 & & 0.050 & \\
\hline \multirow{3}{*}{ Layer 4} & $d$ & 0.03 & Wood & 0.03 & Wood \\
\hline & $C$ & 1.520 & & 1.520 & \\
\hline & $k$ & 0.190 & & 0.190 & \\
\hline \multicolumn{2}{|l|}{ Roads } & \multicolumn{2}{|c|}{ Asphalt (60\%) } & \multicolumn{2}{|c|}{ Concrete $(40 \%)$} \\
\hline \multirow[t]{3}{*}{ Layer 1} & $d$ & 0.04 & Asphalt & 0.04 & Concrete \\
\hline & $C$ & 1.940 & & 1.280 & \\
\hline & $k$ & 0.750 & & 0.250 & \\
\hline \multirow[t]{3}{*}{ Layer 2} & $d$ & 0.20 & Stone aggregate & 0.20 & Stone aggregate \\
\hline & $C$ & 2.000 & & 2.000 & \\
\hline & $k$ & 2.100 & & 2.100 & \\
\hline \multirow[t]{3}{*}{ Layer 3} & $d$ & 0.50 & Gravel/soil & 0.50 & Gravel/soil \\
\hline & $C$ & 1.400 & & 1.400 & \\
\hline & $k$ & 0.400 & & 0.400 & \\
\hline \multirow[t]{3}{*}{ Layer 4} & $d$ & 0.50 & Gravel/soil & 0.50 & Gravel/soil \\
\hline & $C$ & 1.400 & & 1.400 & \\
\hline & $k$ & 0.400 & & 0.400 & \\
\hline \multicolumn{2}{|l|}{ Walls } & \multicolumn{2}{|r|}{ Stone $(80 \%)$} & \multicolumn{2}{|c|}{ Wood shutters $(20 \%)$} \\
\hline \multirow[t]{3}{*}{ Layer 1} & $d$ & 0.01 & Stone & 0.01 & Shutter \\
\hline & $C$ & 2.250 & & 0.450 & \\
\hline & $k$ & 2.190 & & 0.090 & \\
\hline \multirow{3}{*}{ Layer 2} & $d$ & 0.04 & Stone & 0.04 & Shutter \\
\hline & $C$ & 2.250 & & 0.450 & \\
\hline & $k$ & 2.190 & & 0.090 & \\
\hline \multirow[t]{3}{*}{ Layer 3} & $d$ & 0.15 & Stone & 0.15 & Air \\
\hline & $C$ & 2.250 & & 0.150 & \\
\hline & $k$ & 2.190 & & 0.0012 & \\
\hline \multirow[t]{3}{*}{ Layer 4} & $d$ & 0.06 & Stone & 0.06 & Glass \\
\hline & $C$ & 2.250 & & 1.660 & \\
\hline & $k$ & 2.190 & & 0.740 & \\
\hline
\end{tabular}

wind regime (Grimmond et al. 2004, their Fig. 8). As expected, under strong mistral winds the fraction of radiation given to convection is greater, and to storage is less, than with the lighter sea breezes. However, attempts to demonstrate this dependence in the IOP dataset proved fruitless. This was probably due to the fact that the IOP was short, contained no mistral days, and covered a relatively small range of speeds (Fig. 3).

Taken as a group the four ensemble mean estimates of heat storage change (Fig. 5a) follow a daily course that mimics that found for simpler surfaces (e.g., Oke 1987; Guyot 1998). The time of the midday peak differs 


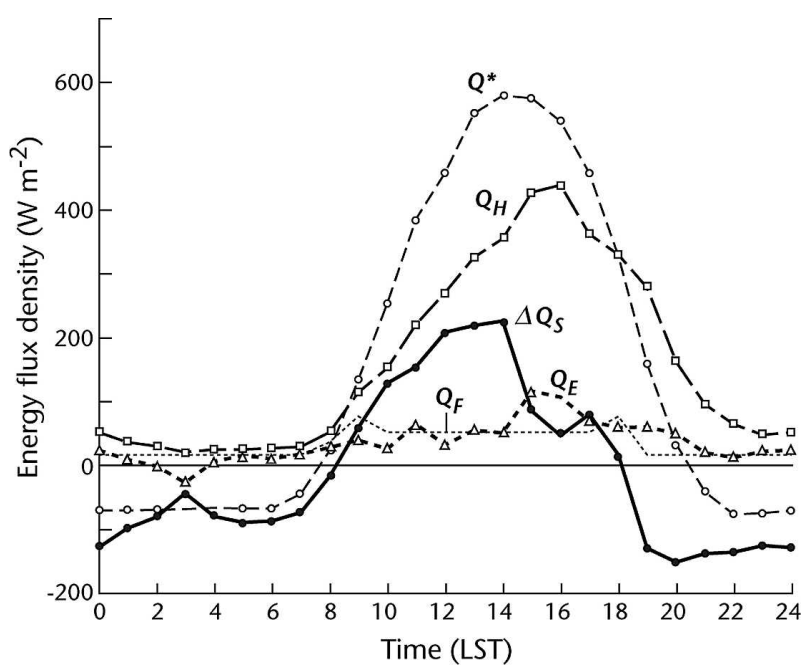

FIG. 4. Mean surface energy balance fluxes for the period YD 185-192 at the central site in Marseille.

by about an hour between all methods and the times of the maximum evening release from storage differ by about $3 \mathrm{~h}$. The range of the magnitudes at any $1 \mathrm{~h}$ is, however, relatively large (typically $75-100 \mathrm{~W} \mathrm{~m}^{-2}$ ) as are their standard deviations, especially for RES.

\section{b. OHM results}

Over the diurnal period, OHM handles the magnitude of the heat flux to and from the substrate reasonably well (Figs. 5 and 6 ) in the mean. However, in the late afternoon and evening it fails to release stored heat sufficiently rapidly and throughout the night values are consistently too low (Fig. 6a). The nocturnal release appears to be capped around $\sim 60 \mathrm{~W} \mathrm{~m}^{-2}$. This may be because in the studies that produced the $a$ coefficients for individual surfaces they were not part of a geometric canyon system where cooling has to consider the interaction with other surfaces and the large thermal inertia of the whole system. Thus, whereas the overall agreement between OHM and RES is fairly good (a bias of only $\sim 36 \mathrm{~W} \mathrm{~m}^{-2}$, Table 4 ), this masks the fact that OHM performs less well in following short-term variations of storage change. The OHM produces a smoother daily march of storage uptake and release than the other methods and is less responsive to temporal features like the sharp drop in the late afternoon, the time of the afternoon-evening turnover (from uptake to release), and the large release of heat after sunset. As a result, hysteresis between $\Delta Q_{S}$ and $Q^{*}$ in the OHM estimates is not as strong as that of RES, especially in the early evening (Fig. 6b). The $a$ coefficients used in the OHM for the Marseille site were compiled from published values of $\Delta Q_{S}$ versus $Q^{*}$ for

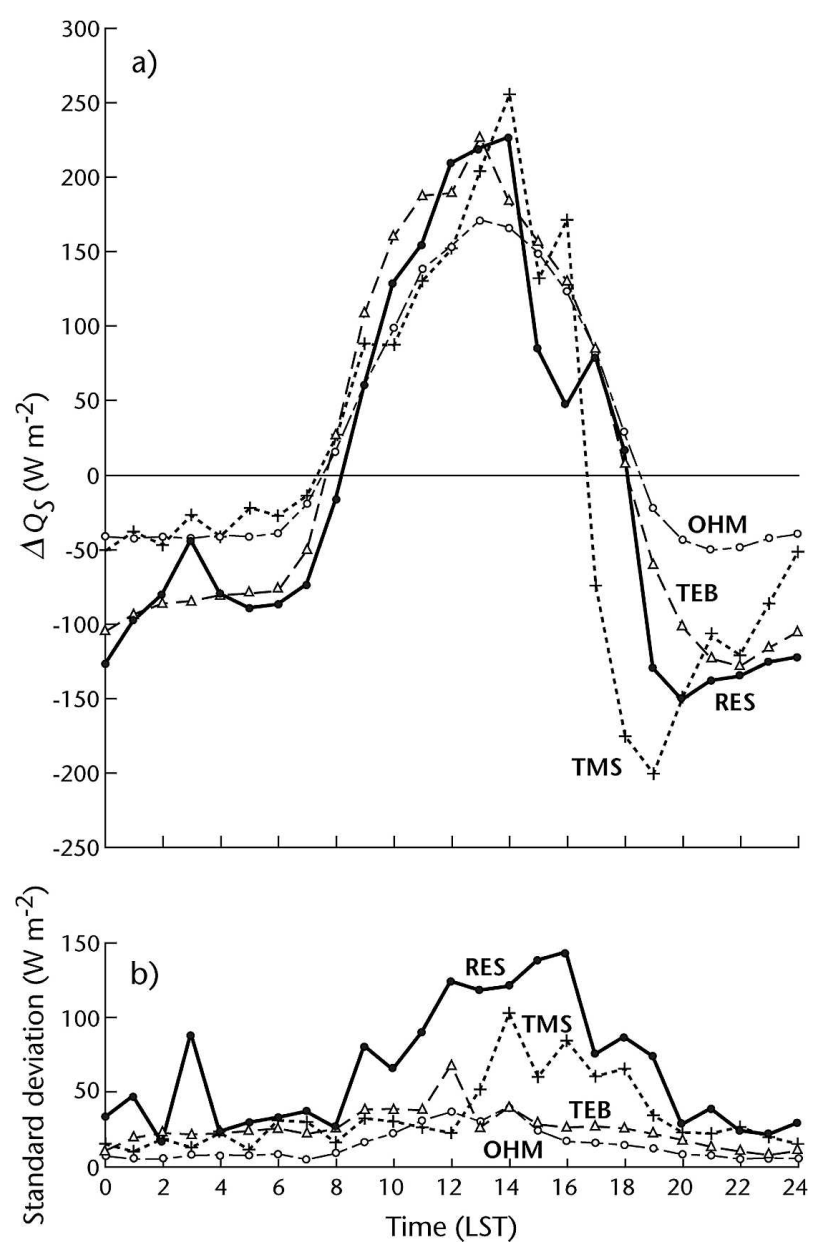

FIG. 5. Ensemble means of the diurnal cycles of storage heat flux from (a) the residual (RES) and modeled methods (OHM, TEB, and TMS) and (b) their standard deviation, for the period YD 185-192 at the central Marseille site.

surface types found in the Marseille site area. The averaged values used in applying (2) are $a_{1}=0.307, a_{2}=$ $0.335 \mathrm{~h}$, and $a_{3}=-20.3 \mathrm{~W} \mathrm{~m}^{-2}$. The values calculated from a statistical fit to the OHM versus $\mathrm{Q}^{*}$ fluxes (Fig. $6 \mathrm{~b})$ gives $a_{1}=0.363, a_{2}=0.596 \mathrm{~h}$, and $a_{3}=-75.8 \mathrm{~W}$ $\mathrm{m}^{-2}$. Only the slope coefficients of the two relations are roughly comparable; the other two that represent the degree and direction of hysteresis and the point of the $y$ intercept are in poor agreement.

Comparison between the performance of $\mathrm{OHM}$ at Marseille and other urban sites (Table 5) confirms that the parameterization is not as well suited to estimate the diurnal behavior of energy storage at this site. The performance for Marseille is about the poorest for any city in the comparison (note the relatively low slope). It may be relevant that the largest rmse values in Table 5 are from Tucson, Arizona, and Marseille; both are dry and windy environments. The relatively large rmse at 

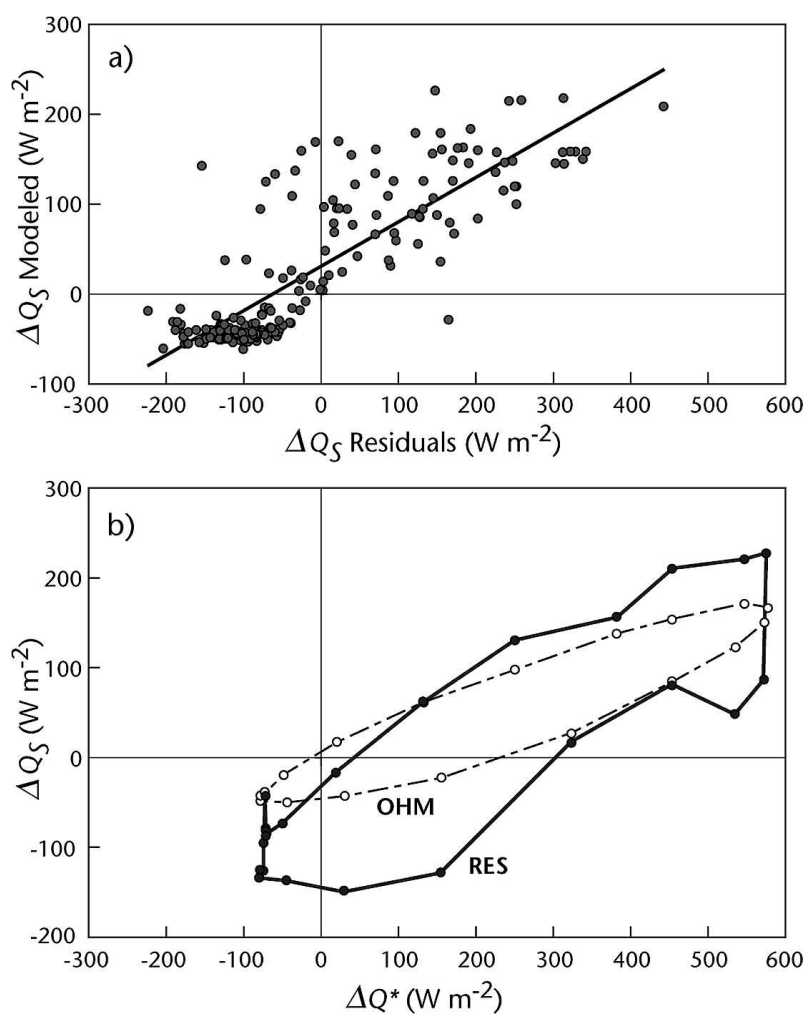

FIG. 6. Comparison of residual (RES) and modeled (OHM) estimates of heat storage flux for YD 185-192 in central Marseille: (a) scatterplot and (b) hysteresis relation between storage estimates from each method and net all-wave radiation.

both sites is probably due in part to the fact that $\mathrm{OHM}$ does not explicitly consider sharing sensible heat between conduction and convection (i.e., the scheme does not include any turbulent parameters). This lacuna is exacerbated by the lack of moisture because almost all heat is in the sensible form. Overall, OHM produces an index of agreement $d$ of only 0.81 , which is considered barely satisfactory.

Given the foregoing we might anticipate the OHM results to be sensitive to wind speed. However, in the daytime, while OHM slightly "overpredicts" storage, even at low wind speeds, it shows little relation to wind speed up to about $6 \mathrm{~m} \mathrm{~s}^{-1}$. At greater speeds there is some indication of a change to "underprediction" relative to RES. This is the reverse of what might be expected, but the small sample precludes further analysis. At night OHM consistently underpredicts the nocturnal heat release from the urban fabric, by about $60-70 \mathrm{~W}$ $\mathrm{m}^{-2}$ (Table 4). Again, the bias is greatest at higher wind speeds. This is more consistent with the analysis of OHM estimates for other cities (Grimmond and Oke 1999). The size of the nocturnal bias is a concern because at that time it is a large fraction of the total en- ergy budget. However, nocturnal measurements of turbulent fluxes are likely to have larger errors so that RES may be too large.

\section{c. TEB results}

The TEB results given here focus on the simulated SEB, with emphasis on sensible heat exchanges. Discussion of other properties simulated by TEB for the Marseille site, such as canyon air temperatures, canyon and roof surface temperatures, and radiation fluxes, are given by Lemonsu et al. (2004). Averaged energy fluxes computed by the model are compared with measurements (Fig. 7), and a summary of the performance statistics for this IOP is given in Tables 4 and 6 .

Considering the dynamic and convective instability observed at this complex urban site, TEB suitably resolves each measured component of the SEB $\left(Q^{*}, Q_{H}\right.$, $\left.Q_{E}\right)$. There is some bias in its handling of the magnitude of $Q^{*}$, which is primarily due to the tendency of the model to overestimate longwave emission from the walls (Lemonsu et al. 2004). Although TEB successfully simulates the positive $Q_{H}$ observed at night, it consistently slightly underestimates this flux at all times of day. Lemonsu et al. (2004) speculate that this underestimation is related to the lack of roof-level mixing resolved by TEB. Modeled $Q_{E}$ also shows good agreement with observations. TEB's consistent overestimation of $\Delta Q_{S}$ results in a simulated daytime $\Delta Q_{S} / Q^{*}$ ratio of 0.29 , as compared with the observed (RES) value of 0.20 .

The ensemble time series of simulated $\Delta Q_{S}$ (Fig. 5a) and the corresponding scatterplot (Fig. 8a) show TEB to agree more closely with RES than OHM does, especially at night (slope $=-0.52$, intercept $=-35.31 \mathrm{~W}$ $\mathrm{m}^{-2}$ ). An exception is the time of the maximum heat release in the evening, which is later in TEB than for the other three methods (Fig. 5a). The model, therefore, reasonably captures the observed relation between $\Delta Q_{S}$ and $Q^{*}$. The hysteresis loop produced by TEB (Fig. 8b) is of approximately the same shape as that observed. The overall upward shift of the TEB loop relative to that of RES is mostly related to the relative overestimation of energy uptake by the model for most daytime hours. The evening lag in release is also evident.

There is no obvious dependence of TEB estimates on wind for speeds less than $6 \mathrm{~m} \mathrm{~s}^{-1}$ by day and hardly at all at night. Except for the case of high daytime ventilation TEB is fairly free of bias resulting from wind. While this might be anticipated, given that TEB uses wind speed as an input and calculates heat exchange using a network of aerodynamic resistances, it is worth mentioning this lack of bias as a good feature. There is 


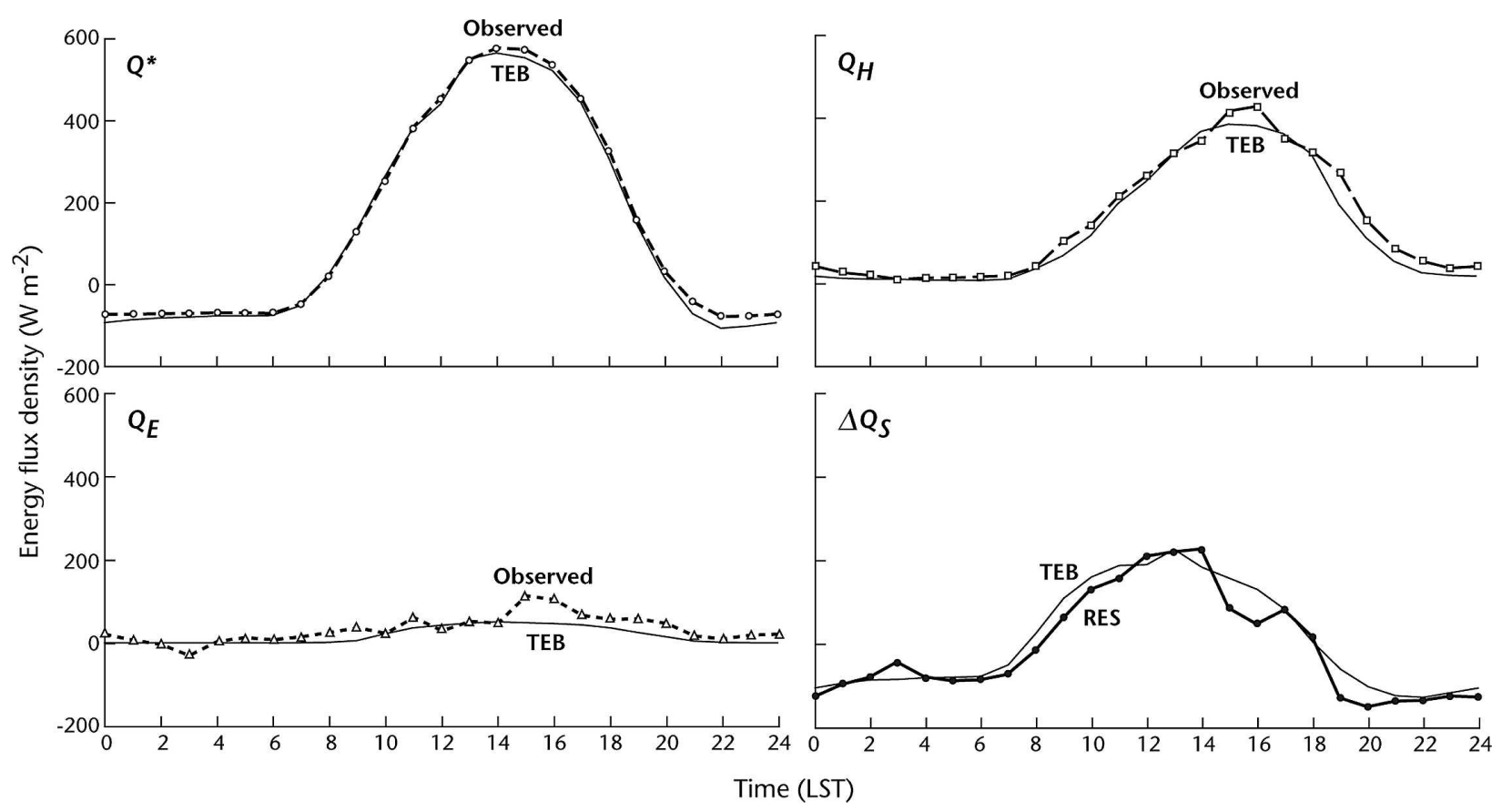

FIG. 7. Comparison of the ensemble mean values of the residual (RES) and modeled (TEB) components of the surface energy balance for YD 185-192 at the central Marseille site.

a minor tendency for TEB to overpredict $\Delta Q_{S}$ at all but the highest wind speeds; the majority of errors are $<50$ $\mathrm{W} \mathrm{m} \mathrm{m}^{-2}$ by day and $<10 \mathrm{~W} \mathrm{~m}^{-2}$ at night (Table 6 ). In summary, TEB predictions are in good agreement with RES and have the lowest rmses of the three methods at all wind speeds and at all times of day. Of course, we suspect that RES values are probably too large; if that is true it means TEB also overpredicts.

\section{d. TMS results}

On average the TMS results (Figs. 5 and 8) are in good agreement with those from the RES approach

TABLE 4. Summary of results and comparative statistics for three methods to approximate $\Delta Q_{S}$ at a site in central Marseille vs residual estimates (RES). Daytime: $Q^{*}>0$. Nighttime: $Q^{*}<0$. Bias $=$ modeled - RES. All units: $\mathrm{W} \mathrm{m}^{-2}$.

\begin{tabular}{llrrr}
\hline \hline Time period & Method & $\Delta Q_{S}$ & Bias & Rmse \\
\hline Daily period & RES & -9 & & \\
& OHM & 27 & 36 & 95 \\
& TEB & 10 & 19 & 79 \\
Daytime & TMS & -2 & 7 & 109 \\
& RES & 67 & & \\
& OHM & 84 & 17 & 111 \\
Nighttime & TEB & 97 & 30 & 101 \\
& TMS & 41 & -26 & 137 \\
& RES & -99 & & \\
& OHM & -42 & 58 & 72 \\
& TEB & -94 & 5 & 40 \\
& TMS & -54 & 45 & 62 \\
\hline
\end{tabular}

(slope 0.901 , intercept $-26.5 \mathrm{~W} \mathrm{~m}^{-2}$ ) with an overall daily bias of only $7 \mathrm{~W} \mathrm{~m}^{-2}$ (Table 4). The scheme underestimates the daytime uptake by $-26 \mathrm{~W} \mathrm{~m}^{-2}$ and the nighttime release by $45 \mathrm{~W} \mathrm{~m}^{-2}$. The main difference from the other methods is the existence of sharp shortterm departures from the diurnal pattern (Fig. 5a), especially the maximum release in the late afternoon (1700-2000 LST). As a result the TMS hysteresis loop is very different in shape to that of RES (Fig. 8b).

Because the surface cover fractions and the thermal properties of the built surfaces are fixed and observed interior surface temperatures are relatively stable (average weighted interior wall temperature $29^{\circ} \mathrm{C}$, standard deviation $1.3^{\circ} \mathrm{C}$ ), the apparent sensitivity of the scheme is attributable to large changes in exterior gradients $\Delta T / \Delta t$ (the sampling interval $\Delta t$ is $15 \mathrm{~min}$.). The early afternoon spike in storage uptake (beginning at about 1300 LST) and the subsequent midafternoon dive toward energy release are interesting. An explanation for this behavior is given by the average storage uptake/ release by each surface type (roof, wall, road) of the urban system represented in TMS (Fig. 9). In energetic terms, the road component is always the largest contributor to heat uptake or release. While roofs are the largest built-up volume (35\%) and are highly exposed to insolation, this is counteracted by their relatively low heat capacity $\left(\sim 0.995 \mathrm{MJ} \mathrm{m}^{-3} \mathrm{~K}^{-1}\right)$ and albedo (0.22; the highest of all the surfaces; Table 2). Thus, roofs experience a large diurnal range of temperature but 
TABLE 5. Statistical performance of OHM in Marseille (this study, indicated in boldface) and at other urban sites, relative to RES estimates. Fluxes are determined for hours when all four 15-min periods are from acceptable wind directions. Sites are ordered by increasing RMSE; $N$ is the total number of hours analyzed. Non-Marseille data are from Grimmond and Oke (1999).

\begin{tabular}{lrccrr}
\hline \hline \multicolumn{1}{c}{ Site/description } & $N$ & Slope & Intercept $\left(\mathrm{W} \mathrm{m}^{-2}\right)$ & $r^{2}$ & $\mathrm{Rmse}^{2}\left(\mathrm{~W} \mathrm{~m}{ }^{-2}\right)$ \\
\hline Los Angeles, California (residential suburb) & 424 & 0.97 & 4.0 & 0.92 & 29.0 \\
Mexico City (city center) & 61 & 0.89 & -6.8 & 0.96 & 33.6 \\
Vancouver (light industrial) & 312 & 0.96 & -4.5 & 0.88 & 48.9 \\
Miami, Florida (residential suburb) & 204 & 0.98 & 22.9 & 0.79 & 61.9 \\
Suburban Vancouver & 464 & 0.75 & 30.8 & 0.67 & 62.9 \\
Sacramento, California (residential suburb) & 222 & 0.55 & 5.0 & 0.56 & 66.0 \\
Chicago, Illinois (residential suburb) & 163 & 0.81 & 38.8 & 0.56 & 83.3 \\
Marseille (city center) & $\mathbf{1 9 2}$ & $\mathbf{0 . 4 9}$ & $\mathbf{3 1 . 0}$ & $\mathbf{0 . 7 0}$ & $\mathbf{9 4 . 8}$ \\
Tucson (residential suburb) & 75 & 1.21 & 66.1 & 0.75 & 107.4 \\
\hline
\end{tabular}

rather than store the heat they shed it by convection, because they are very exposed to ventilation. The role of the massive walls is less than that of both the roofs and the roads because their solar exposure is low in summer (unfavorable angle and greater time in shade) and their heat capacity is relatively high $(\sim 1.894 \mathrm{MJ}$ $\mathrm{m}^{-3} \mathrm{~K}^{-1}$ ), reducing their diurnal surface temperature range. The heat input is therefore small and does not evoke a strong thermal response. Roads are the most energetically significant part of the system despite their relatively short solar day (especially the north-southoriented street canyons). Part of this is attributable to their low albedo (0.08) and intermediate heat capacity, which produce a thermally responsive surface that experiences large short-term surface temperature gradients (e.g., $\sim 8^{\circ} \mathrm{C}$ over a 15 -min sampling period) upon initial exposure to sun and shade. These large temperature gradients produce sudden shifts in the rate of heat uptake and release such as the late-morning "spike" in energy uptake by the roads and the subsequent rapid dip toward the early evening energy release.

Differences between TMS and RES estimates are

TABLE 6. Performance statistics for mean hourly values of the surface energy balance components simulated by the TEB scheme. Bias $=$ modeled - RES. All units: $\mathrm{W} \mathrm{m}^{-2}$.

\begin{tabular}{llrrrr}
\hline \hline \multirow{5}{*}{ Overall period } & & $Q^{*}$ & $Q_{H}$ & $Q_{E}$ & $\Delta Q_{S}$ \\
& RES & 155 & 163 & 34 & -9 \\
& TEB & 142 & 143 & 17 & 10 \\
& Bias & 13 & -20 & -17 & 19 \\
& Rmse & 29 & 56 & 55 & 79 \\
Nighttime & RES & 343 & 267 & 57 & 67 \\
& TEB & 329 & 242 & 31 & 97 \\
& Bias & -10 & -23 & -26 & 30 \\
& Rmse & 33 & 72 & 67 & 101 \\
& RES & -67 & 39 & 8 & -99 \\
& TEB & -83 & 24 & 0 & -94 \\
& Bias & -17 & -15 & -8 & 5 \\
& Rmse & 23 & 26 & 36 & 40 \\
\hline
\end{tabular}

sensitive to wind speed, especially at speeds above about $5 \mathrm{~m} \mathrm{~s}^{-1}$. The individual values of both are expected to show a dependence on wind, but it is unclear why their difference should. It is possible that it relates to differences in the environments that each samples as its source area. RES derives most of its dependence from the convective fluxes, and that may originate preferentially from the environment closer to roof level, whereas TMS sampling reflects more of the in-canyon environment. Wind penetration into the canyons is a function of above-roof wind speed with skimming flow prevalent in areas with deep canyons. This is aided in the daytime by the tendency for in-canyon stability because the interior of canyons is cooler than the environment at roof level. At night, when the thermal stratification is the reverse, the wind effect is comparable for all schemes.

\section{Conclusions}

Application of the four approaches to estimate the urban energy storage flux at a densely built-up site in central Marseille shows broad agreement in the predicted average diurnal course and magnitude. This is both helpful and reassuring because no one method is considered to be a standard. The methodological approaches of the methods are very different; they include measurement, modeling, and parameterization. They also vary greatly in simplicity of application. The broad convergence of their results is therefore very satisfactory.

The objective hysteresis model of Grimmond et al. (1991), which uses hourly averaged values of measured net radiation and simple surface properties to parameterize $\Delta Q_{S}$, does not perform as well at the Marseille site as it has at several other urban sites. Whilst giving reasonable estimates overall, the model does not capture short-term temporal characteristics or the degree 

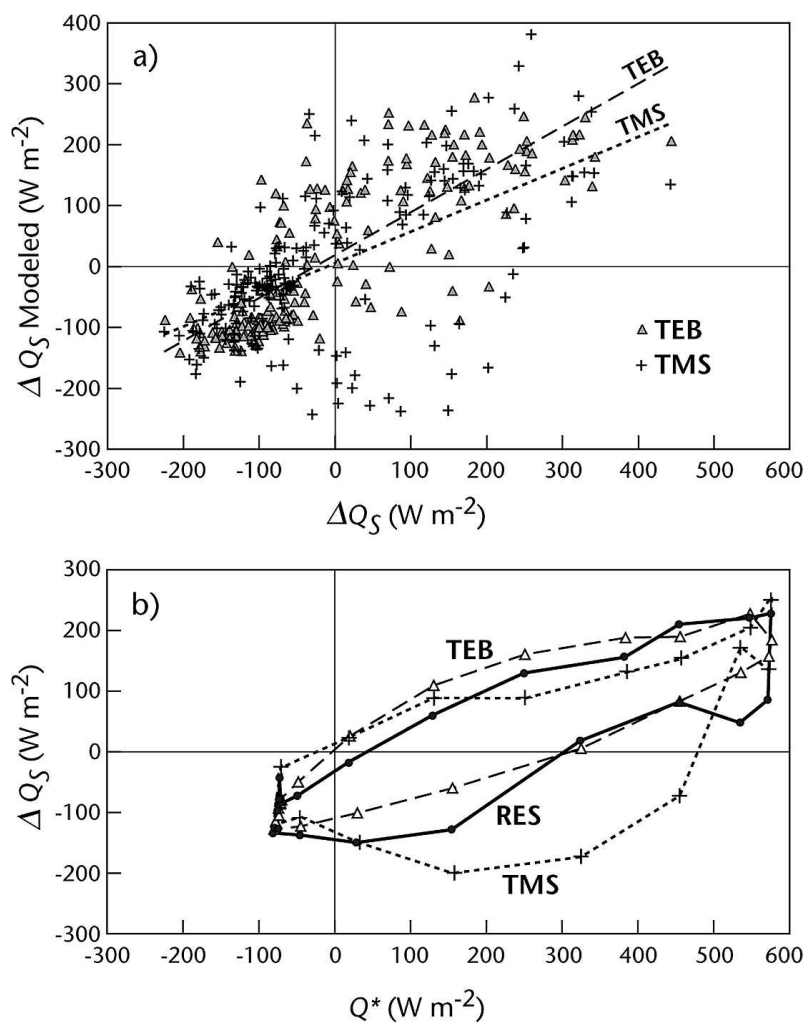

FIG. 8. Energy balance residual (RES) and modeled (both TEB and TMS) storage heat fluxes for YD 185-192 at the central Marseille site: (a) scatterplot and (b) hysteresis loops with the net all-wave radiation.

of hysteresis between $\Delta Q_{S}$ and $Q^{*}$ well. Part of this lack of fidelity occurs because the current OHM formulation does not explicitly incorporate the influence of wind on $\Delta Q_{S}$. The scheme shows the bias primarily at higher wind speeds. It also consistently underpredicts the release of stored heat in the early evening and is still low throughout the night. However, given the relative simplicity of its input requirements and its performance here and elsewhere, OHM remains useful, especially in the mean. When built into numerical urban climate models it has been shown to improve their performance. As suggested by Grimmond and Oke (1999) it seems likely that the OHM could be improved by including a means of allowing increased convective losses with strong winds. This is likely to be of the greatest utility in dry climates.

Considering the complexities of the flow regime at this site and of the site properties in such a densely built-up district, the Town Energy Balance model simulates $\Delta Q_{S}$ remarkably well, especially at night. Other than the observed energy balance residual approach, TEB showed the best ability to reproduce surface energetics under varying stability and synoptic-, meso-,

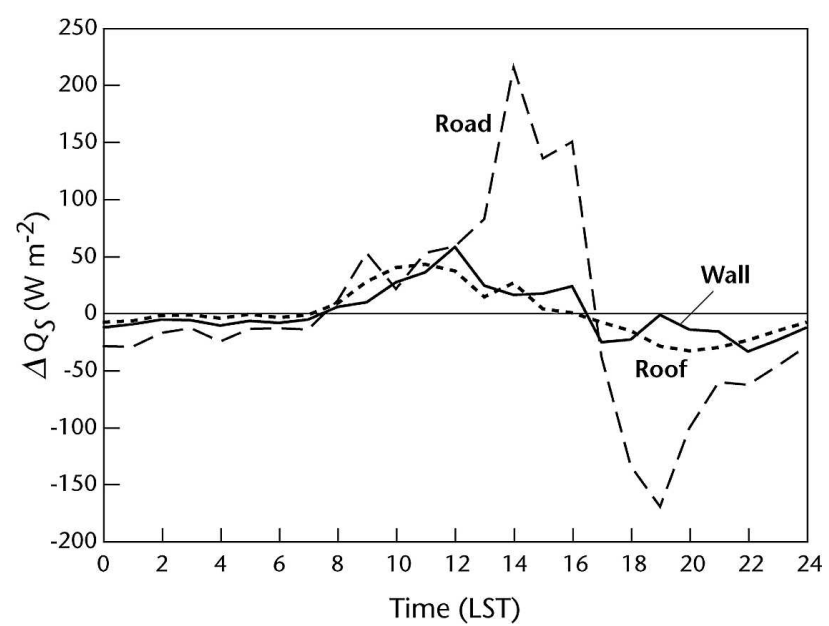

FIG. 9. Ensemble mean $\Delta Q_{S}$ of the three built surfaces (roads, walls, roofs) using the TMS method, which when combined form the TMS urban system.

and local-scale flow regimes at this site and under these synoptic conditions. TEB also seems to be able to simulate the asymmetric sharing of sensible heat between the processes of heat conduction and convection to and from the urban system. Relative to the arbitrary standard set by RES estimates TEB has a tendency to slightly overpredict energy storage most of the time. Of course it could be that RES estimates are too low or that both estimates are not correct.

The thermal mass scheme, while generating results comparable to those from the other methods, is demanding and laborious in its measurement and surface description requirements. As used here this renders TMS impractical for routine use. The method relies on measured surface temperature gradients that vary considerably between the different facets of an urban system resulting from differences of surface materials, orientation, and wind currents. Part of the temporal variability in the TMS results is probably due to insufficient spatial sampling of the gradients. Remotely sensed surface temperatures that incorporate a wide variety of surface facets may be able to provide more stable results.

Overall, the convergence of results between the methods is reassuring in that none of the independent methods divergences greatly in magnitude or timing from the others. This suggests the general form of storage behavior shown by the envelope of curves is probably approximately correct. However, we have no basis on which to judge which method is best. Given the lack of an absolute standard and the spread of the results, we can conclude that heat storage change remains a source of significant imprecision in the measurement and modeling of urban energy balances. Future re- 
search should seek ways to refine estimates of urban heat storage. But, given their commingling and interaction that means improving methods to assess the measured radiative and turbulent heat fluxes and the anthropogenic and advective heat fluxes at urban sites.

Acknowledgments. We are grateful to the Cours Administratives d'Appel for the use of their property as the base for mounting instruments and to Drs. A. Lemonsu, B. Offerle, J. Noilhan, J. Salmond, C. Souch, and V. Masson, and to P. Jackson, G. Pigéon, and C. Walsh for assistance in the field and in running the TEB model. Thanks are given also to the ESCOMPTE meteorological team for weather forecasts. Funding for this project was provided by the Natural Sciences and Engineering Research Council of Canada (TO), the Canadian Foundation for Climate and the Atmospheric Sciences (TO GR-022), National Science Foundation (SG BCS-0095284), Météo-France (TO, SG), and UBL/CLU-ESCOMPTE (TO, SG), which is supported by two programs of the Centre National de la Recherche Scientifique.

\section{REFERENCES}

Anandakumar, K., 1999: A study on the partition of net radiation into heat fluxes on a dry asphalt surface. Atmos. Environ., 33, 3911-3918.

Asaeda, T., and V. T. Ca, 2000: Characteristics of permeable pavement during hot summer weather and impact on the thermal environment. Build. Environ., 35, 363-375.

ASHRAE, 1993: Handbook of Fundamentals (SI). American Society of Heating, Refrigerating, and Air-Conditioning Engineers, $1455 \mathrm{pp}$.

Ching, J. K. S., 1985: Urban-scale variations of turbulence parameters and fluxes. Bound.-Layer Meteor., 33, 335-361.

Christen, A., and R. Vogt, 2004: Energy and radiation balance of a central European city. Int. J. Climatol., 24, 1395-1421.

Doll, D., J. K. S. Ching, and J. Kaneshiro, 1985: Parameterization of subsurface heating for soil and concrete using net radiation data. Bound.-Layer Meteor., 32, 351-372.

Grimmond, C. S. B., 1992: The suburban energy balance: Methodological considerations and results for a mid-latitude west coast city under winter and spring conditions. Int. J. Climatol., 12, 481-497.

— , and T. R. Oke, 1999: Heat storage in urban areas: Localscale observations and evaluation of a simple model. J. Appl. Meteor., 38, 922-940.

$\longrightarrow$, and $\longrightarrow, 2002$ : Turbulent heat fluxes in urban areas: Observations and a Local-scale Urban Parameterization Scheme (LUMPS). J. Appl. Meteor., 41, 792-810.

- H. A. Cleugh, and T. R. Oke, 1991: An objective heat storage model and its comparison with other schemes. Atmos. Environ., 25B, 311-326.

_ , J. Salmond, T. R. Oke, B. Offerle, and A. Lemonsu, 2004: Flux and turbulence measurements at a densely built-up site in Marseille: Heat, mass (water, carbon dioxide), and mo- mentum. J. Geophys. Res., 109, D24101, doi:10.1029/ 2004JD004936.

Guyot, G., 1998: Physics of the Environment and Climate. Wiley, $632 \mathrm{pp}$.

Harrison, R. B., B. McGoldrick, and C. G. B. Williams, 1984: Artificial heat release from Greater London, 1971-1976. Atmos. Environ., 18, 2291-2304.

Ichinose, T., K. Hanaki, and T. Matsuo, 1994: Analyses on geographical distribution of urban anthropogenic heat based on very precise geographical information (in Japanese). Protc. Environ. Eng. Res., 31, 263-273.

_, K. Shimodozono, and K. Hanaki, 1999: Impact of anthropogenic heat on urban climate in Tokyo. Atmos. Environ., 33 (24-25), 3897-3909.

Kerschgens, M. J., and J. M. Hacker, 1985: On the energy budget of the convective boundary layer over an urban and rural environment. Contrib. Atmos. Phys., 58, 171-185.

Kłysik, K., 1996: Spatial and seasonal distribution of anthropogenic heat emissions in Łódź, Poland. Atmos. Environ., 30, 3397-3404.

Lemonsu, A., C. S. B. Grimmond, and V. Masson, 2004: Modelling the surface energy balance of an old Mediterranean city core. J. Appl. Meteor., 43, 312-327.

Masson, V., 2000: A physically-based scheme for the urban energy budget in atmospheric models. Bound.-Layer Meteor., 94, 357-397.

- C. S. B. Grimmond, and T. R. Oke, 2002: Evaluation of the Town Energy Balance (TEB) scheme with direct measurements from dry districts in two cities. J. Appl. Meteor., 41, 1011-1026.

Mestayer, P., and Coauthors, 2005: The urban boundary-layer field campaign in Marseille (UBL/CLU-ESCOMPTE): Setup and first results. Bound.-Layer Meteor., 114, 313-365.

Meyn, S. K., 2000: Heat fluxes through roofs and their relevance to estimates of urban heat storage. M.S. thesis, Department of Earth and Ocean Sciences, The University of British Columbia, $106 \mathrm{pp}$.

Narita, K., T. Sekine, and T. Tokuoka, 1984: Thermal properties of urban surface materials: Study on heat balance at asphalt pavement. Geogr. Rev. Japan, 57, 639-651.

Noilhan, J., and S. Planton, 1989: A simple parameterization of land surface processes for meteorological models. Mon. Wea. Rev., 117, 536-549.

Offerle, B., C. S. B. Grimmond, and K. Fortuniak, 2005: Heat storage and anthropogenic heat flux in relation to the energy balance of a central European city center. Int. J. Climatol., 25, 1405-1419.

Oke, T. R., 1987: Boundary Layer Climates. 2d. ed. Routledge, $435 \mathrm{pp}$.

, 1988: The urban energy balance. Progress Phys. Geogr., 12, 471-508.

_ 2004: Initial guidance to obtain representative meteorological observations at urban sites. Instruments and Methods of Observation Programme IOM Rep. 81, WMO/TD No. 1250, 51 pp. [Available online at http://www.wmo.int/web/www/ IMOP/publications/IOM-81/IOM-81-UrbanMetObs.pdf.]

—- and H. A. Cleugh, 1987: Urban heat storage derived as energy budget residuals. Bound.-Layer Meteor., 39, 233-245.

_, G. T. Johnson, D. G. Steyn, and I. D. Watson, 1991: Simulation of surface urban heat islands under "ideal" conditions at night, Part 2: Diagnosis of causation. Bound.-Layer Meteor., 56, 339-358.

— , R. Spronken-Smith, E. Jáuregui, and C. S. B. Grimmond, 
1999: The energy balance of central Mexico City during the dry season. Atmos. Environ., 33, 3919-3930.

Peikorz, G., 1987: Die Energiebilanz einer stadtischen Struktur. Diplomarbeit, Department of Meteorology, Rheinische Friedrich-Wilhelms-Universität, Bonn, Germany.

Pigeon, G., A. Lemonsu, V. Masson, and P. Durand, 2003: Seatown interactions over Marseille-Part II: Consequences on atmospheric structure near the surface. Proc. of the 5th Int. Conf. on Urban Climate, O30.3, Łódź, Poland, International Association for Urban Climate, 4 pp.

, P. Durand, V. Masson, and S. Grimmond, 2006: Impact of horizontal advection on surface flux estimates over heterogeneous terrain. First iLEAPS Science Post Conf. Workshop, Flux Measurements in Difficult Conditions, A Specialist Workshop, Boulder, CO, iLEAPS.

Roth, M., and T.R. Oke, 1994: Comparison of modelled and "measured" heat storage in suburban terrain. Contrib. Atmos. Phys., 67, 149-156.

Sailor, D. J., and L. Lu, 2004: A top-down methodology for developing diurnal and seasonal anthropogenic heating profiles for urban areas. Atmos. Environ., 38, 2737-2748.

Salmond, J. A., T. R. Oke, C. S. B. Grimmond, S. Roberts, and B. Offerle, 2005a: Wavelet analysis of carbon dioxide fluxes in the urban boundary layer at night. J. Appl. Meteor., 44, 11801194

,,,---- , and,$- 2005 \mathrm{~b}$ : Venting urban canyons of heat, CO2 at night. Bull. Amer. Meteor. Soc., 86, 1546-1547.

Schmid, H.-P., 1997: Experimental design for flux measurements: Matching scales of observations and fluxes. Agric. For. Meteor., 87, 179-200.

- H. A. Cleugh, C. S. B. Grimmond, and T. R. Oke, 1991: Spatial variability of energy fluxes in suburban terrain. Bound.-Layer Meteor., 54, 249-276.

Souch, C., C. S. B. Grimmond, and C. Wolfe, 1998: Evaporation rates for wetlands with different disturbance histories: Indiana Dunes National Lakeshore. Wetlands, 18, 216-229.

Taha, H., 1997: Urban climates and heat islands: Albedo, evapotranspiration, and anthropogenic heat. Energy Build., 25, 99103.

Voogt, J. A., and T. R. Oke, 1997: Complete urban surface temperatures. J. Appl. Meteor., 36, 1117-1132.

Wilkes, K. E., 1989: Model for roof thermal performance. Building Thermal Envelopes and Materials Program, Oak Ridge National Laboratory Rep. ORNL/CON-274, 78 pp.

Wilson, K., and Coauthors, 2002: Energy balance closure at FLUXNET sites. Agric. For. Meteor., 113, 223-243. 